\title{
Clinical Usefulness of Speech Mapping for Fitting of Hearing Aids
}

\author{
So Yean Kim, Jin Su Park, and Min-Beom Kim \\ Department of Otorhinolaryngology-Head and Neck Surgery, Kangbuk Samsung Hospital, \\ Sungkyunkwan University School of Medicine, Seoul, Korea
}

\section{보청기의 적합 과정에서 스피치 매핑의 임상적 유용성}

김소연 · 박진수 · 김민범

성균관대학교 의과대학 강북삼성병원 이비인후과학교실

Received July 20, 2017

Revised August 25, 2017

Accepted August 28, 2017

Address for correspondence

Min-Beom Kim, MD

Department of Otorhinolaryngology-

Head and Neck Surgery,

Kangbuk Samsung Hospital,

Sungkyunkwan University

School of Medicine,

29 Saemunan-ro, Jongno-gu,

Seoul 03181, Korea

Tel $+82-2-2001-2264$

Fax $+82-2-2001-2273$

E-mail minbeom.kim@gmail.com
Background and Objectives The aim of this study was to evaluate the usefulness of speech mapping based on real ear measurement for routine hearing aid fitting and to compare functional gains for evaluating subjective satisfaction of hearing aid users.

Subjects and Method Twenty two participants with bilateral symmetric $(<10 \mathrm{~dB}$ HL difference) sensorineural hearing loss were enrolled in this study. All participants were fitted unilateral hearing aids with speech mapping using the National Acoustic Laboratories-Nonlinear 2 formula. After the initial fitting, patients were followed with the 2nd and 3rd fitting at two weeks and six weeks, respectively, and measured for aided pure tone average (PTA), aided speech discrimination score (SDS), the difference between target gain and real ear insertion gain (REIG) using speech mapping and subjective satisfaction via Korean Adaptation of the International Outcome Inventory for Hearing Aids (K-IOI-HA) questionnaire before further fitting was performed. We analyzed correlation of each parameter at 2 nd and 3rd fitting with the K-IOI-HA score.

Results Every sequential aided PTA and SDS at 2nd fitting and 3rd fitting were significantly improved after repeated hearing aid fitting (all $p<0.01$ ). In the correlation analysis between K-IOI-HA and each parameter, the aided PTA and aided SDS did not show significant correlations with subjective satisfaction from the $2 \mathrm{nd}$ and $3 \mathrm{rd}$ fittings. But the difference between the target gain and REIG in speech mapping showed significant negative correlations with the satisfaction scores at various speech level ( $\mathrm{r}=-0.609$ to -0.709 , all $p<0.01)$.

Conclusion Speech mapping using real ear measurement was useful to expect subjective satisfaction of hearing aid users and it would be a valuable tool for fine tuning to achieve individual preferences.

Korean J Otorhinolaryngol-Head Neck Surg 2018;61(6):287-94

Key Words Auditory threshold $\cdot$ Hearing aids $\cdot$ Hearing loss $\cdot$ Questionnaire.

\section{서 론}

보청기의 적합(hearing aid fitting)은 환자 청력 손실의 특 성을 고려하여 가장 적절한 형태의 보청기를 선택한 후 음향

This is an Open Access article distributed under the terms of the Creative Commons Attribution Non-Commercial License (http://creativecommons.org/licenses/by-nc/4.0) which permits unrestricted non-commercial use, distribution, and reproduction in any medium, provided the original work is properly cited.
이득과 출력 음압을 결정하는 과정이다. 보청기를 처방한 후 에는 보청기 증폭 기능을 통한 음향학적 이득을 평가하기 위한 보청기의 기계적 검증(verification)이 필요하며 환자가 보청기를 착용함으로써 일상 생활에 얼마나 도움을 받고 만 족하는지를 확인하는 보청기의 기능적 확인(validation)도 필요하다. 보청기를 착용한 후 환자가 얼마나 말소리를 정확 하고 편안하게 잘 알아들을 수 있는지를 측정하고 환자의 귀 
에 알맞게 조절해주는 과정은 필수적으로 중요한 일이다.

환자의 청력 역치에 근거한 처방법으로 보청기를 처방한 후 에는 목표만큼 이득을 전달하는지 기계적 검증을 통해 보청 기 자체의 기능을 확인해야 한다. 이를 측정하는 방법은 크 게 세 가지로 방음실 내의 스피커를 통해 음이 방사되는 음장 (sound field)에서 보청기를 착용하지 않은 상태와 착용한 상 태에서 주관적인 청각 음향학적 측정을 하여 기능적 이득 (functional gain)을 계산하는 음장 측정(sound field measurement), 실제 외이도 내에서 보청기를 사용한 경우와 사용 하지 않은 경우의 청력 역치를 객관적으로 측정하여 실이삽입 이득(real ear insertion gain, REIG)을 계산하는 실이 측정 (real ear measurement), $2 \mathrm{cc}$ 접합기를 사용하여 보청기의 음 향학적 이득을 객관적으로 평가하는 접합기 반응(coupler response) 등이 있다. ${ }^{1)}$

실이 측정은 실제 환자의 외이도 내부의 고막 가까이에 실 리콘 재질의 probe microphone관을 삽입하여 보청기를 착 용하지 않은 상태와 착용한 상태에서 각각 외이도 내부의 음 향학적 특성의 $\mathrm{dB}$ sound pressure level을 측정하는 방법이 다. 이 방법은 객관적인 검사로써 주관적으로 측정되는 기능 적 이득과 달리 환자가 응답하지 않아도 되므로 어린 유소아 에서도 시행할 수 있으며 검사 시간이 적게 소요되는 장점이 있다. 여러 가지 입력음과 음압에 있어 각 주파수에서 보청기 에 의해 증폭된 음압이 보청기를 착용하지 않았을 때의 실이 공명반응(real ear unaided response, REUR)에 비해서 얼마 나 증가하였는지 실이삽입이득(REIG)을 측정하여 목표 이 득(target gain)과 얼마나 차이가 나는지를 구하여 보청기의 이득을 조절할 수 있다.2)

Speech mapping은 실이 측정을 기반으로 한 보청기의 기계 적 검증방법으로 검사를 위해서 순음 신호(pure tone signal) 를 사용하지 않고 일상 생활에서 접하는 대화나 음악, 말소 리 등을 활용하는 장점이 있다. 순음 신호의 경우 최근 디지털 보청기의 잡음 제거(noise reduction) 기능, 음향 되울림 제거 (acoustic feedback cancellation) 기능에 의해 잡음이나 되울 림으로 받아들여져 보청기의 적절한 성능의 평가에 어려움이 있을 수 있으나 말소리를 활용하는 경우 이러한 오류를 피할 수 있다. 또한 speech mapping의 결과가 청력도(audiogram) 의 형태로 바로 보여지기 때문에 환자의 이해를 도와 순응도 를 높이는 데 도움을 줄 수 있다. ${ }^{3)}$

저자들은 보청기의 적합 과정에 있어 오래전부터 통상적 으로 사용되고 있는 음장청력검사(sound field audiometry) 와 speech mapping을 비교하고, 어떠한 방법이 환자의 주관적 만족도를 예측하는 데 있어 우수한지 확인해 보고자 하였다.

\section{대상 및 방법}

\section{대 상}

2013년 5 7월 강북삼성병원에 내원하여 보청기를 착용하 게 된 환자를 대상으로 후향적 분석을 진행하였다. 대상 기준 은 40 70 dB의 청력 역치를 보이는 중등도 및 중등고도 난청 이면서 양측 청력 역치의 차이가 $10 \mathrm{~dB}$ 미만인 양측 대칭성 감각신경성 난청 환자들을 대상으로 하였다. 이 중 소아, 전음 성 난청, 추적 소실, 뇌혈관 질환이나 인지 장애 등 신경학적 기저 질환을 가진 환자들은 제외하여 총 22 명의 대상자를 선 정하였다. 환자군의 평균 나이는 69.5세, 성별은 남자 7명, 여 자 15 명, 보청기 착용 방향은 우측 9 명, 좌측 13 명이었다.

\section{검사방법}

각 대상자에서 처음 보청기를 맞추기 위해 외래를 내원하 였을 때(1차 fitting) 보청기 미착용 시의 음장순음청력검사 [unaided pure tone average(PTA)]와 어음청력검사[unaided speech discrimination score(SDS)]를 시행하였다. 모든 대상 자는 Aurical FreeFit ${ }^{\circledR}$ (Otometrics, Taastrup, Denmark)을 이용하여 National Acoustic Laboratories-Nonlinear 2 formula를 통해 일측성의 보청기 적합과 speech mapping을 시 행하였다. Speech mapping에서는 250, 500, 1000, 2000, $4000,8000 \mathrm{~Hz}$ 의 6개 각 주파수에서 목표 이득(target gain) 과 실이삽입이득(REIG)의 차이를 구하여 더한 총합을 분석 하였다.

대상자들은 1차 적합으로부터 2주 후(2차 적합)와 6주 후 (3차 적합) 경과 시 외래로 내원하여 보청기 착용 시의 음장순 음역치(aided PTA)와 어음명료도(aided SDS)를 측정하였으 며, speech mapping에서는 250 8000 Hz 의 각 주파수에서 목표 이득과 실이삽입이득(REIG)의 차이를 구하여 더한 총 합을 분석하였다. 보청기로 증폭된 소리가 환자에게 얼마나 주관적인 만족감을 주는지를 확인하기 위한 기능적 확인으 로서 Korean Adaptation of the International Outcome Inventory for Hearing Aids $(\mathrm{K}-\mathrm{IOI}-\mathrm{HA})$ 설문지를 시행하였다. 우리는 2차 적합과 3차 적합 시 시행한 음장청력검사 및 speech mapping의 여러 측정값과 $\mathrm{K}-\mathrm{IOI}-\mathrm{HA}$ 설문지를 통한 주관적 만족감과의 상관관계를 분석하였다(Fig. 1).

\section{Sound field audiometry}

음장에서의 주관적 역치(subjective threshold) 측정은 이중 방음벽으로 구성된 방음실 안에서 Madsen Astera ${ }^{2}$ audiometer ${ }^{\circledR}$ (Otometrics)와 이에 장착되어 있는 2개의 external free-field amplifier speaker를 사용하였다. 환자와 스피커 


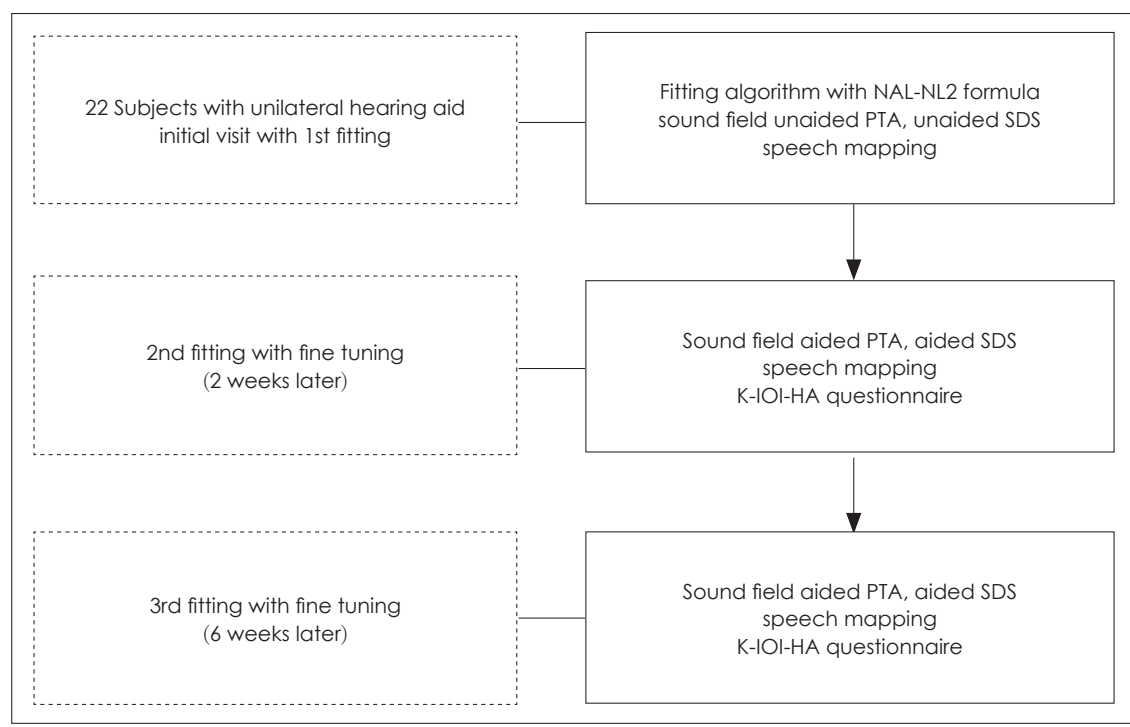

Fig. 1. Shown is the design of the study. NAL-NL2: National Acoustic Laboratories- nonlinear 2, PTA: pure tone average, SDS: speech discrimination score, K-IOI-HA: Korean Adaptation of the International Outcome Inventory for Hearing Aids.
의 거리를 $1 \mathrm{~m}$ 로 하고 각 스피커는 환자의 양측 $45^{\circ}$ 방위각 (azimuth)에 위치시킨 후 변조 순음(warble tone)으로 측정 하였다. 검사 주파수는 250, 500, 1000, 2000, 4000, 8000 $\mathrm{Hz}$ 로 하여 측정하였다. 보청기 착용 시 순음청력역치(aided $\mathrm{PTA}$ ), 어음명료도(aided SDS), 보청기 착용에 따른 기능적 이 득(unaided PTA-aided PTA), 보청기 착용에 따른 어음명료 도의 호전 정도(aided SDS-unaided SDS) 등 총 네 가지 지표 를 2차 적합과 3 차 적합 시에 각각 측정하였다.

\section{Speech mapping}

실이 측정을 통한 객관적인 보청기의 기계적 검증은 Aurical FreeFit ${ }^{\circledR}$ system을 사용하였다. 이 시스템은 환자의 양이와 목에 거치하는 외부 장치(wireless speechlink 100 binaural neckset)와 프로그램(visible speech software)으로 구성되 어 있으며, 양이에 거치하는 2 개의 module은 reference microphone과 실리콘 재질의 유연한 probe microphone으로 이루어져 있다. 주변 잡음이 통제된 음장에서 환자는 정면을 바라보고 이마에서 약 $1 \mathrm{~m}$ 떨어진 거리에 음장 스피커를 위 치시켰다. 검사를 시행하기 전 probe microphone을 reference microphone에 연결시켜 보정(calibration)하였으며, 이경을 통해 환자의 외이도 상태와 길이를 파악한 뒤 probe microphone이 고막에서 2 5 mm 떨어진 곳에 위치할 수 있도록 환 자의 외이도에 삽입하였다. 우리는 speech mapping system 에 보청기 적합 소프트웨어인 NOAH link(HIMSA, Copenhagen, Denmark)를 연결하여 환자의 청력도와 목표 이득값 을 반영한 보청기의 조절이 실시간으로 이루어지도록 하였다. Microphone의 신호 대역은 목에 거치하는 외부 장치의 무선 링크를 통해 컴퓨터에 전달되어 환자의 외이도 내에서의 신

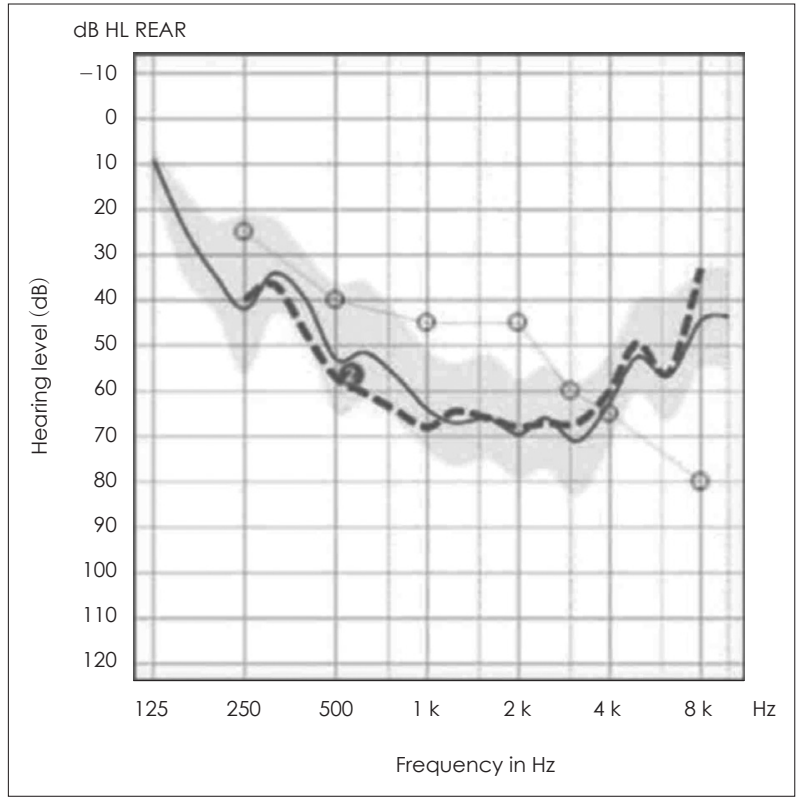

Fig. 2. Verification of unilateral hearing aid on 3 input levels for speech stimuli by the Aurical FreeFit ${ }^{\circledR}$, soft speech level (55 dB $\mathrm{HL})$, comfortable speech level (65 dB HL) and loud speech level (75 dB HL). Figure shows example of speech mapping in comfortable speech level ( $65 \mathrm{~dB} \mathrm{HL}$ ). Shadow area shows spectrum of sounds in the ear canal, solid curve shows real ear aided gain and dotted curve shows real ear unaided gain+target gain. REAR: real ear aided response.

호 스펙트럼을 적합 과정 동안 실시간으로 조절자와 환자에 게 보여주었다. 실제 말소리는 작은 소리 단계(soft speech level, $55 \mathrm{~dB}$ HL), 중간 소리 단계(comfortable speech level, $65 \mathrm{~dB}$ HL), 큰 소리 단계(loud speech level, $75 \mathrm{~dB}$ HL)로 구 분해 제시하여 보청기의 이득을 측정하였다. 참조한 그림 (Fig. 2)에서 점선은 보청기 착용 시 프로그램으로 처방된 목 표 이득에서 실이공명이득(real ear unaided gain)을 합한 역치 
값이며 실선은 보청기를 착용 후 실이증폭이득(real ear aided gain) 수치로 점선과 실선의 차이는 목표 이득과 실이삽입이 득(REIG)의 차이를 나타낸다. 250, 500, 1000, 2000, 4000, $8000 \mathrm{~Hz}$ 의 6개 각 주파수에서 목표 이득과 실이삽입이득 (REIG)의 차이를 구하여 총합을 구하였다.

\section{K-IOI-HA Questionnaire}

보청기 효과의 주관적 평가를 위해 널리 사용되고 있는 설 문지 중의 하나인 International Outcome Inventory for Hearing Aids(IOI-HA)의 한국어 번역판을 사용하였다. 총 7 개의 질문 항목으로 구성되어 있고, 각각의 항목은 보청기 착용 후 일상 생활에서의 보청기 사용 시간(daily use), 이익 (benefit), 보청기 사용에 따른 활동(residual activity), 만족 도(satisfaction), 남아 있는 활동 제한(residual participation restrictions), 타인에 끼치는 영향(impact on others), 삶의 질 (quality of life) 등으로 구성되어 각각 다른 결과 영역을 대 변하고 있다. 각 질문 항목은 5 개의 보기를 선택할 수 있도록
구성되어 있고, 가장 나쁜 결과를 의미하는 보기를 가장 좌 측에 배치하여 1점으로 점수화하고, 우측으로 갈수록 점점 긍정적인 의미의 보기를 설정하고 1점씩 더하여 가장 우측의 보기 항목은 5점으로 정하였다. 각 질문 항목의 점수는 1점 부터 5점까지, 총점은 최소 5점부터 최대 35점까지 표시할 수 있다(Fig. 3). ${ }^{4)}$

\section{분석방법}

통계 처리는 Windows용 SPSS version 18.0(SPSS Inc., Chicago, IL, USA), STATA version 14.0(STATA Corp., LP, $\mathrm{TX}, \mathrm{USA}$ ) 프로그램을 이용하여 분석하였으며 $p$ value가 0.05 미만인 경우를 통계학적으로 유의한 것으로 정의하였 다. 통계 분석에 앞서 모집단에 대한 정규성 검정을 시행하였 으며, 정규 분포를 위배하지 않아 모수적 검정법(parametric statistical test)을 사용하였다. 보청기 적합이 거듭될수록 음장 청력검사에서의 청력 이득에 대한 경향성은 repeated measures ANOVA를 사용하였으며, speech mapping에서의 청력

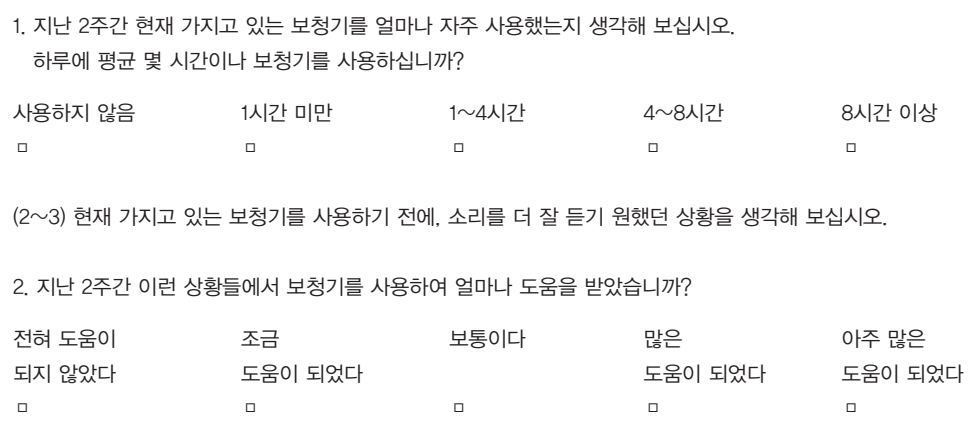
ing Aids questionnaire. 
이득에 대한 경향성은 대응표본 $\mathrm{t}$ 검정(paired $\mathrm{t}$-test of difference)을 사용하여 대표값으로 평균과 표준편차를 제시하였 다. 음장청력검사 및 speech mapping 검사에서의 각 지표와 $\mathrm{K}-\mathrm{IOI}-\mathrm{HA}$ score와의 연관성은 피어슨 상관 분석(Pearson's correlation analysis)과 선형 회귀 분석(linear regression analysis)을 이용하였다.

\section{결 과}

\section{음장청력검사(Sound field audiometry)}

음장에서의 청력 역치는 1차 적합에서 보청기 미착용 시(unaided PTA) 평균 $55.0 \mathrm{~dB}$ 이었으며 2차 적합에서 보청기 착용 시(aided PTA) $37.4 \mathrm{~dB}, 3$ 차 적합에서 보청기 착용 시(aided PTA) $31.4 \mathrm{~dB}$ 로 점차 호전되는 양상을 보였다(Fig. 4A). 음장 에서의 어음명료도의 경우에도 1 차 적합 시 보청기 미착용 시 (unaided SDS) 평균 78.5\%, 2차 적합에서 보청기 착용 시 (aided SDS) 91.0\%, 3차 적합에서 보청기 착용 시(aided SDS) $94.0 \%$ 로 호전을 보였으며 모두 통계적으로 유의한 차이를 보 였다(Fig. 4B).

\section{Speech mapping}

2차 적합에서 목표 이득과 REIG의 차이는 작은 소리 단계 에서 $20.0 \mathrm{~dB}$, 중간 소리 단계에서 $18.0 \mathrm{~dB}$, 큰 소리 단계에서
$15.0 \mathrm{~dB}$ 이었으며 3차 적합에서 목표 이득과 REIG의 차이는 작은 소리 단계에서 $16.8 \mathrm{~dB}$, 중간 소리 단계에서 $12.5 \mathrm{~dB}$, 큰 소리 단계에서 $11.2 \mathrm{~dB}$ 로 나타나 3차 적합 시에는 2 차 적합 시 에 비해 목표 이득과 REIG의 차이가 감소하는 경향을 보였 다. 하지만 대응표본 $\mathrm{t}$ 검정을 이용한 통계 분석에서는 중간 소리 단계에서만 유의한 차이를 보였다 $(p=0.014)$ (Table 1).

\section{$\mathrm{K}-\mathrm{IOI}-\mathrm{HA}$ score와 각 지표와의 상관 분석}

Speech mapping에서의 목표 이득과 REIG의 차이를 비롯 하여 음장청력검사를 이용한 보청기 착용 시 순음청력역치 (aided PTA), 어음명료도(aided SDS), 보청기 착용에 따른 functional gain(unaided PTA-aided PTA), 보청기 착용에 따른 어음명료도의 호전 정도(aided SDS-unaided SDS) 총 다섯 가지 지표와 주관적 만족감을 나타내는 K-IOI-HA questionnaire score 사이에의 상관 분석과 회귀 분석을 시행하 였다.

2차 적합에서는 speech mapping의 작은 소리 단계, 중간 소리 단계, 큰 소리 단계에서의 목표 이득과 삽입 이득 간의 차이가 모두 $\mathrm{K}-\mathrm{IOI}-\mathrm{HA}$ score와 통계적으로 유의한 음의 상 관관계를 보여 목표 이득과 $\mathrm{REIG}$ 의 차이가 감소할수록 $\mathrm{K}-$ IOI-HA score가 증가하는 경향을 보였고, 회귀 분석에서도 모두 음의 회귀 계수가 도출되었으며 통계적으로 유의하였다 (Table 2A), 음장 청력검사에서 측정한 4개의 지표들에서는
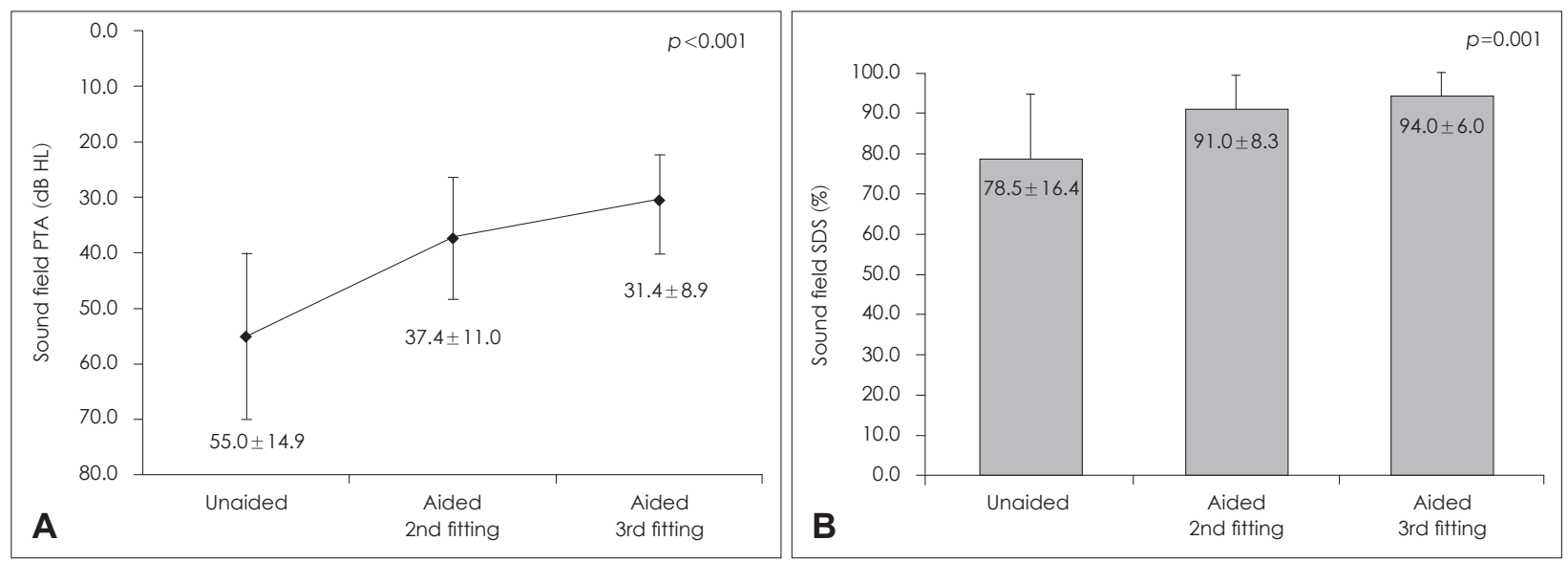

Fig. 4. Sound field PTA calculated using six-frequency average: unaided PTA, aided PTA at 2 nd fitting and aided PTA at 3rd fitting (A). Sound field SDS: unaided SDS, aided SDS at 2nd fitting and aided SDS at 3rd fitting (B). PTA: pure tone average, SDS: speech discrimination score.

Table 1. The gap between target gain and REIG in speech mapping at 2nd and 3rd fitting

\begin{tabular}{lccc}
\hline & Target gain-REIG (2nd fitting) & Target gain-REIG (3rd fitting) & $p$-value \\
\hline Soft speech level $(55 \mathrm{~dB} \mathrm{HL})$ & $20.0 \pm 12.9$ & $16.8 \pm 11.4$ & 0.085 \\
Comfortable speech level $(65 \mathrm{~dB} \mathrm{HL})$ & $18.0 \pm 13.1$ & $12.5 \pm 9.9$ & $0.014^{*}$ \\
Loud speech level $(75 \mathrm{~dB} \mathrm{HL})$ & $15.0 \pm 14.3$ & $11.2 \pm 10.8$ & 0.074 \\
\hline
\end{tabular}

Roughly, the more repeated hearing aid verification, the smaller gap between target gain and REIG. But this tendency has a statistical significance only in comfortable speech level ( $65 \mathrm{~dB} \mathrm{HL}) . * p<0.05$. REIG: real ear insertion gain 
Table 2. The analysis of correlation between K-IOI-HA score and variable parameter on sound field audiometry and speech mapping in 2nd fitting

\begin{tabular}{|c|c|c|c|c|c|}
\hline \multirow{2}{*}{ Target gain-REIG } & \multicolumn{2}{|c|}{ Pearson's coefficient } & \multicolumn{3}{|c|}{ Linear regression } \\
\hline & Correlation coefficient & $p$-value & Regression coefficient $(95 \% \mathrm{Cl})$ & p-value & $R^{2}$ \\
\hline \multicolumn{6}{|l|}{ A } \\
\hline Soft speech level ( $55 \mathrm{~dB} \mathrm{HL})$ & -0.709 & $<0.001^{*}$ & $-0.736(-1.077$ to -0.395$)$ & $<0.001^{*}$ & 0.503 \\
\hline Comfortable speech level ( $65 \mathrm{~dB} \mathrm{HL}$ ) & -0.679 & $0.001^{*}$ & $-0.696(-1.047$ to -0.345$)$ & $0.001^{*}$ & 0.461 \\
\hline Loud speech level (75 dB HL) & -0.609 & $0.003^{*}$ & $-0.570(-0.916$ to -0.224$)$ & $0.003^{*}$ & 0.371 \\
\hline \multicolumn{6}{|l|}{ B } \\
\hline Aided PTA & -0.225 & 0.313 & $-0.055(-0.166$ to 0.056$)$ & 0.313 & 0.051 \\
\hline Functional gain & 0.139 & 0.536 & $0.028(-0.065$ to 0.122$)$ & 0.536 & 0.019 \\
\hline Aided SDS & 0.080 & 0.725 & $0.026(-0.125$ to 0.176$)$ & 0.725 & 0.006 \\
\hline Gain of SDS & 0.085 & 0.706 & $0.013(-0.059$ to 0.086$)$ & 0.706 & 0.007 \\
\hline
\end{tabular}

Correlation between K-IOI-HA score and target gain-REIG (dB) in speech mapping (A), aided hearing threshold, functional gain, aided SDS and gain of SDS in sound field by Pearson's correlation analysis and linear regression analysis $(B) . * P<0.05$. K-IOI-HA: Korean Adaptation of the International Outcome Inventory for Hearing Aids, REIG: real ear insertion gain, SDS: speech discrimination score, PTA: pure tone average, Cl: confidence interval

Table 3. The analysis of correlation between $\mathrm{K}-\mathrm{IO}-\mathrm{HA}$ score and variable parameter on sound field audiometry and speech mapping in 3rd fitting

\begin{tabular}{|c|c|c|c|c|c|}
\hline \multirow{2}{*}{ Target gain-REIG } & \multicolumn{2}{|c|}{ Pearson's correlation } & \multicolumn{3}{|l|}{ Linear regression } \\
\hline & Correlation coefficient & p-value & Regression coefficients (95\% Cl) & $p$-value & $R^{2}$ \\
\hline \multicolumn{6}{|l|}{ A } \\
\hline Soft speech level (55 dB HL) & -0.705 & $<0.001^{*}$ & $-1.548(-2.274$ to -0.821$)$ & $<0.001^{*}$ & 0.497 \\
\hline Comfortable speech level ( $65 \mathrm{~dB} \mathrm{HL}$ ) & -0.684 & $<0.001^{*}$ & $-1.736(-2.601$ to -0.871$)$ & $<0.001^{*}$ & 0.467 \\
\hline Loud speech level (75 dB HL) & -0.662 & $0.001^{*}$ & $-1.534(-2.345$ to -0.724$)$ & $0.001^{*}$ & 0.438 \\
\hline \multicolumn{6}{|l|}{ B } \\
\hline Aided PTA & -0.463 & $0.030 *$ & $-0.260(-0.491$ to -0.028$)$ & $0.030 *$ & 0.215 \\
\hline Functional gain & 0.077 & 0.734 & $0.147(-0.143$ to 0.436$)$ & 0.303 & 0.006 \\
\hline Aided SDS & 0.155 & 0.491 & $0.029(-0.148$ to 0.207$)$ & 0.734 & 0.024 \\
\hline Gain of SDS & -0.053 & 0.813 & $-0.016(-0.156$ to 0.124$)$ & 0.813 & 0.003 \\
\hline
\end{tabular}

Correlation between K-IOI-HA score and target gain-REIG $(\mathrm{dB})$ in speech mapping (A), aided hearing threshold, functional gain, aided SDS and gain of SDS in sound field by Pearson's correlation analysis and linear regression analysis $(B) . * p<0.05$. K-IOI-HA: Korean Adaptation of the International Outcome Inventory for Hearing Aids, REIG: real ear insertion gain, SDS: speech discrimination score, PTA: pure tone average, $\mathrm{Cl}$ : confidence interval

$\mathrm{K}-\mathrm{IOI}-\mathrm{HA}$ score와 통계적으로 유의한 상관관계가 나타내 지 않았다(Table 2B).

3차 적합에서는 speech mapping의 작은 소리 단계, 중간 소리 단계, 큰 소리 단계에서의 목표 이득과 삽입 이득 간의 차이가 모두 K-IOI-HA score와 통계적으로 유의한 음의 상 관관계를 보였고, 회귀 분석에서도 모두 음의 회귀 계수가 도 출되었으며 통계적으로 유의하여 2차 적합 때와 유사한 경향 을 보였다(Table 3A). 그러나 음장청력검사에서 측정한 4개 의 지표 중 보청기 착용 시 순음청력역치(aided PTA)에서만 $\mathrm{K}-\mathrm{IOI}-\mathrm{HA}$ score와 통계적으로 유의한 음의 상관관계를 확 인할 수 있었다(Table 3B).

\section{고 찰}

보청기의 조절은 우선 환자의 청력 상태를 측정하여 처방 공식(prescription formula)을 통해 보청기의 증폭 목표치를 산출하게 된다. 이를 토대로 적합하게 조절된 보청기는 목표 이득에 얼마나 가깝게 소리를 증폭시켜 주고 있는지 객관적 으로 측정되어야 하며, 일상 생활에서 느끼는 주관적인 착용 효과를 알아보기 위하여 보청기 착용 전후의 수행 능력이나 만족도에 대한 평가도 병행되어야 한다. ${ }^{5}$

보청기의 기계적 검증방법 중 음장 측정은 변조 순음(warble tone)이나 협대역의 신호(narrow band signal)를 사용하여 보청기 착용 시 각 주파수에서 역치가 얼마나 낮아졌는지 기 능적 이득을 확인할 수 있다. ${ }^{6}$ 검사방법이 일반 순음청력검사 와 유사하여 비교적 간단하게 측정을 할 수 있어 보청기 적합 및 기계적 검증 시 고전적으로 가장 흔히 시행되는 검사 중 하 나이다. 그러나 일종의 주관적인 검사방법이므로 청력 역치 에 대한 근본적인 신뢰에 한계가 있으며, 검사 시간이 비교적 오래 걸리고 어린 유소아에서 시행이 어렵고 반대 측 귀를 
차폐하고 시행해야 하는 제한점 등이 있다.) 또한 검사 재현 성의 $95 \%$ 신뢰 구간이, 실이측정검사가 $3 \mathrm{~dB}$ 인 데 비해 ${ }^{89)}$ 음 장 이득 측정은 약 $15 \mathrm{~dB}$ 인 점을 고려할 때 ${ }^{10)}$ 재현성이 낮아 실이측정검사가 더 신뢰할 수 있는 검사라고 할 수 있다. ${ }^{11}$

실이 측정은 외이도에서 보청기의 증폭 특성을 측정하는 것으로 보청기 착용 전후의 음압 차이를 비교하여 보청기의 이득을 알아보는 데 사용한다. ${ }^{12)}$ 같은 크기의 소리 자극이라 도 각 대상의 외이도 내에서 형성되는 음압의 크기가 외이도 공명 상태에 따라 달라지므로 소리 압력이 실제 고막 바로 앞 에서 다른 값으로 바뀌게 된다. 성인에서는 대개 $2700 \mathrm{~Hz}$ 와 4000 5000 Hz에서 두 차례 실이 공명 현상이 일어난다. ${ }^{13)}$ 그 로 인해 가령 폐쇄형 보청기를 착용하게 되면 외이도에 새로 형성되는 작은 용적으로 인해 더 큰 소리 압력이 발생될 수 있다. 외이도의 용적, 모양, 부피, 길이와 주위 조직의 물리학 적인 요소들이 관여하는 외이도 공명 상태에 의해 주파수별 음압이 개인마다 달라지게 되므로 실제 귀에서 보청기의 이 득이 어떻게 나타나는지 알아보는 실이 측정의 중요성이 강 조되어 왔다. ${ }^{14}$

실이 측정방법으로 우선 보청기를 착용하지 않은 상태에서 실이공명반응(REUR)을 측정한 후, 같은 상태에서 보청기를 착용하고 실이증폭반응(real ear aided response)을 측정한 다. 실이증폭반응과 실이공명반응과의 차이를 전 주파수 범위 에서 연속적으로 기록한 곡선을 실이삽입반응(real ear insertion response)이라고 하며 각 주파수 별로 실이증폭반응과 실이공명반응과의 차이를 실이삽입이득(REIG)이라고 정의 한다. ${ }^{2)}$ 실이삽입이득(REIG)의 값이 보청기의 처방 공식에서 예측한 목표 이득 및 음장에서 측정한 기능적 이득과 일치하 는가를 확인하며 적합 시 이득을 조절해 주게 된다. ${ }^{2)}$

실이 측정은 보청기 조절 과정 중 환자에게 객관적인 자료 를 보여 줄 수가 있고 함께 참여를 유도하므로 보청기 및 조 절에 대한 신뢰감을 가지게 된다는 장점이 있다. ${ }^{15)}$ 그러나 기 존의 실이 측정은 몇 가지 한계점을 가지고 있다. 우선 검사 시 사용되는 tone이나 noise을 통해 측정한 이득은 실생활에서 의 말소리나 음악과 같은 복합음에 대한 이득과 상당한 차이 를 보인다. 이러한 차이는 보청기 채널의 수, 압축의 속도, 압 축의 역치 때문으로 알려져 있다. ${ }^{11)}$ 또한 피드백 제어 기능이 장착된 고성능의 디지털 보청기에서는 순음으로 주어지는 검 사 신호가 보청기에서 피드백으로 인식될 수 있고, 잡음 억제 기능이 보청기에 장착되어 있다면 측정 시 제시되는 신호가 잡 음으로 간주되어 주파수별 이득을 낮게 책정할 우려가 있다.11

최근에는 tone이나 noise를 이용한 기존 실이 측정에서 나 아가 실제 말소리를 신호음으로 제시하여 보청기 이득을 측 정하는 speech mapping이 각광받고 있다. 'Speech map'은
1992년 Audioscan 사에서 처음으로 도입하여 등록한 보청기 매핑 환경 시스템이다. ${ }^{16)}$ 말소리가 실시간으로 보정 및 조정되 어 제시되며 개개인에 맞는 말소리 가청 영역(speech banana) 이 설정된다. ${ }^{15)}$ 외이도 실이 측정 장치를 삽입하고, 보정(calibration)된 말소리를 들려주면서 증폭된 소리의 장기평균어 음스펙트럼(long-term average speech spectrum)이 환자의 청력에 따른 목표 이득 또는 말소리 가청 영역(speech banana) 범위에 일치하는지를 확인하여 보청기의 이득이나 다른 기능 을 조절할 수 있다. ${ }^{17}$

또한 이 검사는 실제 말소리를 작은 소리(soft speech level, 50 55 dB HL), 중간 소리(comfortable speech level, 65 70 $\mathrm{dB} \mathrm{HL}$ ), 큰 소리(loud speech level, $90 \mathrm{~dB} \mathrm{HL}$ ) 단계로 구분 하여 제시하므로 다양한 강도의 실제 말소리가 편안한 수준 에서 청취되도록 조절할 수 있어 기존 기기에 비해 정교하고 효율적이다. 이러한 측정 과정이 화면에 표시되므로 환자가 시각적으로 가청 영역을 확인하고 보청기 조절 과정에 직접 참 여할 수 있다. ${ }^{18}$

본 연구에서는 보청기의 기계적 검증을 위한 검사로써 speech mapping을 시행하고 보청기 적합이 이루어졌을 때 환 자의 착용 만족도가 기능적 이득을 구하는 음장 측정결과와 비교하였을 때 어떠한 차이가 있는지 밝히고자 하였다.

적합을 거듭할수록 음장청력검사에서는 보청기 착용 시 청력 역치(aided PTA)와 어음명료도가 점차 호전되는 양상을 보이며 모두 통계적으로 유의한 차이를 보였다. 또한 speech mapping에서는 2차 적합 시에 비하여 3차 적합 시에 목표 이 득과 REIG의 차이가 감소하는 경향을 보여 speech mapping 을 바탕으로 한 적합을 반복할수록 목표에 근접한 이득을 줄 수 있음을 시사하였다.

환자의 주관적 만족도와의 상관관계 분석에서 2차 적합과 3 차 적합 시의 speech mapping에서는 작은 소리 $(55 \mathrm{~dB} \mathrm{HL})$, 중간 소리 $(65 \mathrm{~dB} \mathrm{HL})$, 큰 소리 $(75 \mathrm{~dB} \mathrm{HL})$ 단계에서의 목표 이득과 삽입 이득 간의 차이가 모두 K-IOI-HA score와 통 계적으로 유의한 음의 상관관계를 보여 목표 이득과 REIG 의 차이가 감소할수록 K-IOI-HA score가 증가하는 경향을 보였다. 반면 음장청력검사에서 측정한 4 개의 지표 중에서는 3 차 적합 시 보청기 착용 시 순음청력역치(aided PTA)에서 만 K-IOI-HA score와 통계적으로 유의한 음의 상관관계를 확인할 수 있었으며, 이에 대한 상관 계수는 0.463 으로 유의 한 상관관계를 갖는 다른 변수들에 비해 상관관계가 다소 작음을 알 수 있었다. 따라서 speech mapping에서 측정한 보청기의 음향학적 이득과 주관적인 보청기 만족도와의 상 관관계가 음장 측정결과와 주관적인 보청기 만족도와의 상 관관계와 비교하였을 때 상회하는 유의성을 보였다. 
본 연구의 한계점 중 하나는 본 연구에 참여한 피험자가 22 명으로 표본의 크기가 비교적 작고, 양측의 대칭적 중등고도 감각신경성 난청 환자들만을 대상으로 하여, speech mapping의 임상적 유용성 정도를 일반화하여 적용하기는 어려 울 수 있다.

또한 보청기 착용을 통한 주관적 만족감에는 보청기의 음 향학적 이득뿐만 아니라 환자 개개인마다 다른 생활 패턴, 난 청으로 인해 느끼는 활동 제약의 정도에도 영향을 미치게 되 는데 본 연구에서는 그러한 피험자의 특성에 대한 고려가 배 제되어 있다. 동일한 난청 정도를 가진 환자들이 동일한 이 득을 주는 보청기를 착용하여도 소음이 심한 장소에서 많은 시간을 보내는 사람은 만족감이 높지 않을 것이고 조용한 곳 에서 많은 시간을 보내는 사람은 비교적 높은 만족감을 보이 게 될 것이다. 따라서 주관적인 보청기의 기능적 확인을 정량 화한 설문지 평가와 보청기의 음향학적 이득을 통한 객관적 인 보청기의 기계적 검증 간의 경향성을 확인함에 있어 한계 가 있다. 따라서 speech mapping의 임상적 유용성을 입증하 기 위해서는 추후 피험자 수를 늘리고 통계학적으로 표본의 층화 분석(stratification)을 포함한 추가 연구가 필요할 것으 로 생각된다.

\section{REFERENCES}

1) Kodera K, Hosoi H, Okamoto M, Manabe T, Kanda Y, Shiraishi K, et al. Guidelines for the evaluation of hearing aid fitting (2010). Auris Nasus Larynx 2016;43(3):217-28.

2) Yoon TH. Hearing aid fitting and verification. Korean J Audiol 1998; 2(1):17-22.

3) Swan IR, Gatehouse $S$. The value of routine in-the-ear measurement of hearing aid gain. Br J Audiol 1995;29(5):271-7.
4) Chu HS, Cho YS, Park SN, Byun JY, Shin JE, Han GC, et al. Standardization for a Korean adaptationof the international outcome inventoryfor hearing aids: study of validity and reliability. Korean J Otorhinolaryngol-Head Neck Surg 2012;55(1):20-5.

5) Oh SH. Current opinion on hearing aids. 2nd ed. Seoul: Sejong academy;2017. p.447.

6) Cho YS. Clinical Settings for Hearing Aids. Audiol Speech Res 2016; 12 suppl 1:527-32.

7) Tecca JE. Use of real-ear measurements to verify hearing aid fittings. In: Valente M, editors. Strategies for selecting and verifying hearing aid fittings. 2nd ed, New York: Thieme Publishing;1994. p.88-107.

8) Valente M, Valente M, Goebel J. Reliability and intersubject variability of the real ear unaided response. Ear Hear 1991;12(3):216-20.

9) Valente M, Meister M, Smith P, Goebel J. Intratester test-retest reliability of insertion gain measures. Ear Hear 1990;11(3):181-4.

10) Hawkins DB, Montgomery AA, Prosek RA, Walden BE. Examination of two issues concerning functional gain measurements. J Speech Hear Disord 1987;52(1):56-63.

11) Cho YS. Management of Hearing Aids Clinic. Korean J Otorhinolaryngol-Head Neck Surg 2010;53(6):333-9.

12) Chung JH. Rehabilitation of sensorineural hearing loss: hearing aid. Hanyang Med Rev 2015;35(2):97-102.

13) Hong SH, Woo HC, Cho YS, Koh SJ, Shin MH. REUR (real ear unaided response) Performed before hearing aid fitting. Korean J Audiol 1997;1(1):64-9.

14) Noh H, Heo MG, Park SN, Park KH, Yeo SW. Feasibility of Real Ear Measurement for Hearing Aid Fitting in Preschoolers. Korean J Audiol 2010;14(3):181-6.

15) Moore BCJ. Speech mapping is a valuable tool for fitting and counseling patients. Hearing Journal 2006;59(8):26-31.

16) Cole WA, Sinclair ST. The audioscan RM500 speechmap/DSL fitting system. Trends Amplif 1998;3(4):125-39.

17) Cunningham DR, Lao-Davila RG, Eisenmenger BA, Lazich RW. Study finds use of Live Speech Mapping reduces follow-up visits and saves money. Hearing Journal 2002;55(2):43-9.

18) Ross T, Smith KE. How to use live speech mapping as part of a hearing instrument fitting and verification protocol. Hearing Review 2005; 12(6):40-9. 